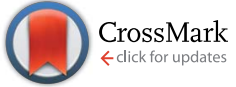

Cite this: RSC Adv., 2015, 5, 27690

\title{
Visible-light photocatalysis on C-doped ZnO derived from polymer-assisted pyrolysis $\uparrow$
}

\author{
Ahmad S. Alshammari, ${ }^{* a}$ Lina Chi, ${ }^{\text {bc }}$ Xiaoping Chen, ${ }^{\text {bc }}$ Abdulaziz Bagabas, ${ }^{a}$ \\ Denis Kramer, ${ }^{\text {b }}$ Abdulaziz Alromaeh ${ }^{a}$ and Zheng Jiang ${ }^{* b}$
}

C-doped ZnO with a large surface area was prepared via F127-assisted pyrolysis at $500{ }^{\circ} \mathrm{C}$ and used for visible-light-responsive photocatalytic water purification. The band structure of the C-doped $\mathrm{ZnO}$ was investigated using valance band XPS and DFT simulation. The C-doped ZnO possessed enhanced absorption of UV and visible light, though it showed lower visible-light-responsive photocatalytic activity than $\mathrm{ZnO}$ because of significant recombination of photogenerated charge carriers arising from overloaded C-dopant and oxygen vacancies.

Received 29th December 2014 Accepted 9th March 2015

DOI: $10.1039 / c 4 r a 17227 b$

www.rsc.org/advances waste water, water splitting and photoelectrochemical cells. ${ }^{7-9,11,20}$ Although synthesis of C-doped $\mathrm{ZnO}$ represents a considerable challenge, a few methodologies have been successfully established, including self-doping via thermal decomposition of $\mathrm{Zn}_{5}\left(\mathrm{CO}_{3}\right)_{2}(\mathrm{OH})_{6}$ precursor, ${ }^{7}$ pyrolysis of $\mathrm{Zn}$ containing inorganic-organic presursors, ${ }^{\mathbf{8 1 4}}$ polymer or carbon templated syntheses, ${ }^{9}$ metal organic chemical vapour deposition (MOCVD) ${ }^{21}$ and thermal plasma in-flight carbonisation techniques. ${ }^{22}$ The polymer-assisted pyrolysis synthesis allows incorporation carbon into $\mathrm{ZnO}$ matrix and improving its porosity. ${ }^{\mathbf{8 1 4}}$ However, different C-doping species or multi-level oxygen vacancies $\left(\mathrm{O}_{\mathrm{vac}}\right)$ would co-existed in the resultant $\mathrm{C}$-doped $\mathrm{ZnO}$ materials, ${ }^{7,23}$ resulting in the difficulty to clarify their origin of visible-light response, so did C-doped $\mathrm{TiO}_{2}{ }^{\mathbf{1 6 , 1 8 , 1 9}}$ In principle, light C-doping may extend visible-light absorption and promote their visiblelight-driven photocatalysis, ${ }^{\mathbf{8 1 2 , 2 3 , 2 4}}$ while heavy C-doping is highly possible to cause recombination of photogenerated charge carriers. Therefore, it is essential to investigate the roles of C-dopant and $\mathrm{O}_{\mathrm{vac}}$ in the harvesting visible-light and visible-light-responsive photocatalysis for C-doped $\mathrm{ZnO}$ with heavy C-doping level.

In this study, Pluronic F127 $\left(\mathrm{EO}_{106} \mathrm{PO}_{70} \mathrm{EO}_{106}\right)$ copolymer was adopted for incorporating carbon into $\mathrm{ZnO}$ and improves its porosity through a polymer-assisted thermal pyrolysis at $500{ }^{\circ} \mathrm{C}$. The crystal phase, morphology, porosity, light absorption properties and carbon species of the received C-doped $\mathrm{ZnO}$ were carefully characterised. The origin of the visible-light response of the C-doped $\mathrm{ZnO}$ was interpreted via valance band XPS and first-principle simulation using CASTEP package. The photocatalysis performance of $\mathrm{ZnO}$ and C-doped $\mathrm{ZnO}$ was comparatively evaluated under visible-light to conclude the roles of C-doping.

\footnotetext{
${ }^{a}$ National Nanotechnology Research Center, King Abdulaziz City for Science and Technology, King Abdullah Road, P.O. Box 6086, Riyadh 11442, Saudi Arabia. E-mail: aalshammari@kacst.edu.sa; Tel: +9660114814285

${ }^{b}$ Faculty of Engineering and The Environment, University of Southampton, Southampton, SO17 1BJ, UK. E-mail: z.jiang@soton.ac.uk; Tel: +44 (0) 2380594893

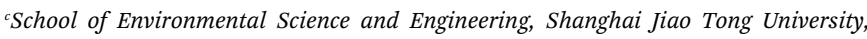
Shanghai, 200240, China

$\uparrow$ Electronic supplementary information (ESI) available: Fig. S1 PDOS of (a) O and (b) Zn in Wurtzite ZnO crystal; Fig. S2, Methylene Blue Photodegradation over ZnO and C-doped ZnO with different C-doping levels. See DOI: 10.1039/c4ra17227b
} 


\section{Experimental and computational}

\subsection{Sample preparation}

All the chemicals were of reagent-grade and were used as purchased from Sigma-Aldrich Company without further purification. Deionized water was used in all experiments.

In the synthesis of C-doped $\mathrm{ZnO}, 5.9 \mathrm{~g}$ of $\mathrm{Zn}\left(\mathrm{NO}_{3}\right)_{2} \cdot 6 \mathrm{H}_{2} \mathrm{O}$ was dissolved in $50 \mathrm{ml}$ of mixed solution of deionized water and ethanol (water-ethanol = 1: 1 in volume ratio) to form a clear solution, then $0.75 \mathrm{~g}$ of $\mathrm{F} 127 \mathrm{was}$ added. The resulting mixed solution was moved into an electric oven at $90{ }^{\circ} \mathrm{C}$ and heated overnight to vapour solvents and form dry polymer metalorganic complex. The dry complex was calcined in muffle furnace up to $500{ }^{\circ} \mathrm{C}$ for 3 hours in a $2{ }^{\circ} \mathrm{C} \mathrm{min}{ }^{-1}$ heating ramp. For comparison, a pristine $\mathrm{ZnO}$ was also prepared in the same procedure without addition of F127.

\subsection{Characterisation}

X-Ray diffraction (XRD) patterns were obtained on a Philip $\mathrm{X}^{\prime}$ Pert $\mathrm{D}$ using $\mathrm{Cu}-\mathrm{K} \alpha 1$ radiation at a scan rate of $0.05^{\circ} 2 \theta \mathrm{s}^{-1}$ and were used to determine the phase structures of the samples. Transmission electron microscopy (TEM) analysis was conducted using a JEM-2100F microscope (JEOL, Japan) at a $200 \mathrm{kV}$ accelerating voltage. Photocatalyst samples were dispersed in water-methanol and treated with ultrasound for 5 min before deposited on a carbon coated grid.

Brunauer, Emmett, and Teller (BET) surface areas and pore size distribution of the photocatalysts were obtained on Micrometrics Gemini III-2375 (Norcross, GA, USA) instrument by $\mathrm{N}_{2}$ physisorption at $-196^{\circ} \mathrm{C}$. Prior to the measurements, the catalyst was evacuated for $2 \mathrm{~h}$ at $150{ }^{\circ} \mathrm{C}$ to remove physically adsorbed water. The BET surface area was determined by a multipoint BET method using the adsorption data in the relative pressure $\left(P / P_{0}\right)$ range of $0.05-0.3$.

The UV-vis diffuse reflectance spectra were obtained on Perkin Elmer Lambda 950 UV/Vis/NIR spectrophotometer equipped with a $150 \mathrm{~mm}$ snap-in integrating sphere for capturing diffuse and specular reflectance. $\mathrm{BaSO}_{4}$ was used as a reflectance standard in the UV-visible diffuse reflectance experiment.

X-Ray photoelectron spectroscopy (XPS) measurements were performed on the ESCALAB-210 spectrometer (Thermo VG Scientific, UK) with an $\mathrm{Mg}-\mathrm{K} \alpha$ source. All the binding energies were referenced to the $\mathrm{C} 1 \mathrm{~s}$ peak at $284.6 \mathrm{eV}$ of the surface adventitious carbon.

\subsection{Photocatalytic activity}

The photocatalytic activity of the prepared samples in terms of the photocatalytic decolorization of methylene blue (MB) aqueous solution was performed at ambient temperature under visible-light irradiation using a $300 \mathrm{~W}$ Xe lamp $(15 \mathrm{~cm}$ above the dishes) with a $400 \mathrm{~nm}$ cutoff filter as a light source.

In the photocatalysis experiments, $0.1 \mathrm{~g}$ of the prepared photocatalyst powder was dispersed in a $100 \mathrm{~mL} \mathrm{MB}$ aqueous solution with a concentration of $10 \mathrm{ppm}$ in a beaker. The mixed solution was remained in dark for an hour to establish an MB solution adsorption-desorption equilibrium on the photocatalyst before light irradiation. During photocatalysis, the $4 \mathrm{~mL}$ reaction solution was taken out in every 15 min irradiation interval and filtered to measure the concentration change of $\mathrm{MB}$ using a UV-visible spectrophotometer (Scinco, Neosys-2000, South Korea). Since the MB was at rather low concentration in the aqueous solution, its photodegradation followed a pseudofirst-order reaction and its kinetics can be expressed as

$$
-\ln \left(c / c_{0}\right)=k t
$$

where $k$ is the apparent rate constant and $c_{0}$ and $c$ are the initial and reaction concentrations of aqueous MB solution, respectively.

\subsection{Computational details}

The density function theory (DFT) calculations of $\mathrm{ZnO}$ and C-doped $\mathrm{ZnO}$ were performed with the CASTEP package using the generalized gradient approximation (GGA), ${ }^{25}$ in the scheme of Perdew-Burke-Ernzerhof (PBE) to describe the exchangecorrelation functional. The norm-conserving pseudopotential was adopted rather than ultrasoft pseudopotential because the former is more suitable to simulate the bandgap and optical properties.

For simulating C-doping effects, we first built a $2 \times 2 \times 2$ (32-atom) wurtzite $\mathrm{ZnO}$ supercell, containing $16 \mathrm{Zn}$ and $16 \mathrm{O}$, in which one $\mathrm{O}$ atom was replaced by a $\mathrm{C}$ atom, corresponding to $\mathrm{C}$ doping level of 6.25 at.\%. The crystal parameters of wurtzite $\mathrm{ZnO}$ unit cell in the DFT calculation are $a=3.249 \AA$ and $c=5.205 \AA$. The Monkhorst-Packgrid for SCF calculation is $7 \times 7 \times 4$ with $16 k$ points was used for integration in the Brillouin zone of the supercell, ${ }^{26}$ and the plane-wave kinetic energy cutoff was set to $600 \mathrm{eV}$. The mechanical equilibrium was achieved through conjugate gradient minimization of the total energy to a tolerance of $2 \times 10^{-6} \mathrm{eV}$ per atom, the maximum forces to a tolerance of $0.05 \mathrm{eV} \AA^{-1}$, and the maximum atomic displacement position tolerance of $1 \times 10^{-3} \AA$. The $2 \times 2 \times 2$ (32-atom) wurtzite $\mathrm{ZnO}$ supercell was also simulated as reference.

\section{Results and discussion}

\subsection{Crystal and textural properties}

Fig. 1(a) comparatively shows the XRD patterns of pure and C-doped $\mathrm{ZnO}$ samples calcined at $500{ }^{\circ} \mathrm{C}$. All the Bragg diffraction peaks of the $\mathrm{ZnO}$ and $\mathrm{C}$-doped $\mathrm{ZnO}$ samples can be well indexed according to hexagonal wurtzite $\mathrm{ZnO}\left(\mathrm{Pb}_{3} \mathrm{mc}\right.$, JCPDS: 890511), though the C-doped ZnO shows weaker diffraction intensity than $\mathrm{ZnO}$, indicating that C-doped $\mathrm{ZnO}$ possesses lower crystallinity or smaller crystallite size. The close observation to the strongest peaks (Fig. 1(b)) shows the Cdoping leads to (101) diffraction shifting to higher $2 \theta$ angle, which is ascribed to doping-induced unit cell deformation. As listed in Table 1, the calculated crystallite size, lattice parameters and unit cell volume of C-doped $\mathrm{ZnO}$ are indeed smaller than those of pure $\mathrm{ZnO}$. The C-doping induced $\mathrm{ZnO}$ lattice parameters reduction and cell volume shrinking can be 

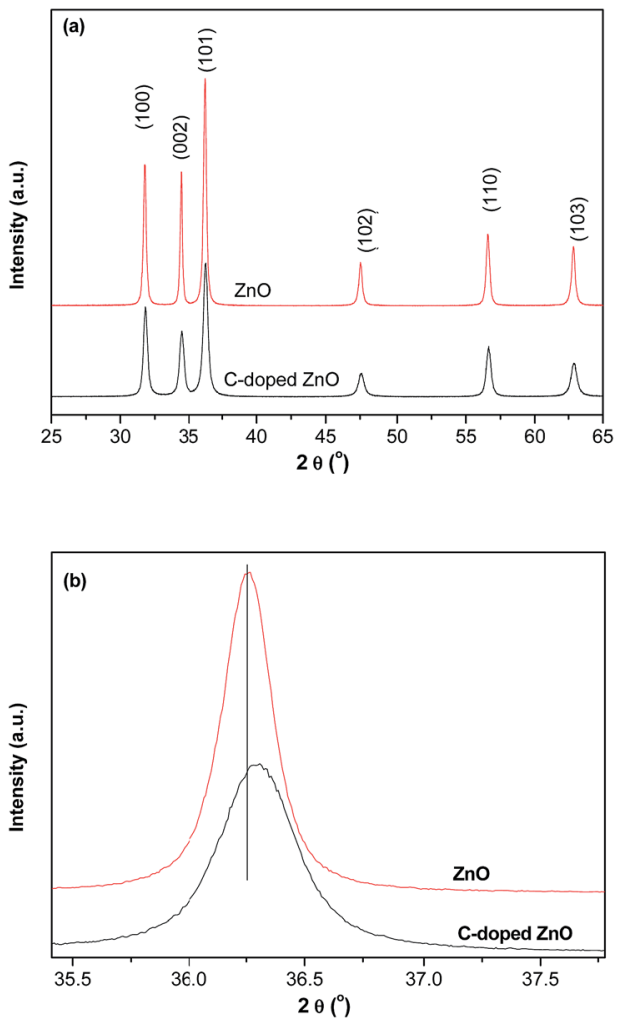

Fig. 1 (a) Full and (b) amplified XRD patterns of the pristine $\mathrm{ZnO}$ and $\mathrm{C}$ doped $\mathrm{ZnO}$ calcined at $500{ }^{\circ} \mathrm{C}$.

reasonably attributed to structure defects $\left(\mathrm{O}_{\mathrm{vac}}\right)$ caused by C-doping. If there were no $\mathrm{O}_{\mathrm{vac}}$, the lattice parameters should have been increased because the carbon anion radius (69-76 pm) is greater than oxygen (57-66 pm). From the charge equilibrium point of view, substitution of $\mathrm{O}(-\mathrm{II})$ by $\mathrm{C}(-\mathrm{rv})$ would unbalance system charge that requires oxygen loss to remain system neutral. The results agree with previous research where C-doping induced unit cell changes were also observed. ${ }^{22}$

Transmission electron microscope (TEM) was used to further investigate the morphology and crystal structures of $\mathrm{ZnO}$ and C-doped ZnO. It can be seen from the TEM images (Fig. 2) that $\mathrm{ZnO}$ and $\mathrm{C}$-doped $\mathrm{ZnO}$ are in nano-flake morphology (Fig. 2(ai) and (bi)), but C-doped ZnO nanoflakes show more regular hexagonal shape and smaller particle size $(\sim 20 \mathrm{~nm})$ than that of pure $\mathrm{ZnO}(\sim 30 \mathrm{~nm})$, which is well consistent with XRD results. The HRTEM images of $\mathrm{ZnO}$ and C-doped ZnO are presented in Fig. 2(aii) and (bii), in which the labelled lattice fringes (Fig. 2(aiii) and (biii)) are attributed to $d$ spacings between adjacent (100) and (101) surfaces,

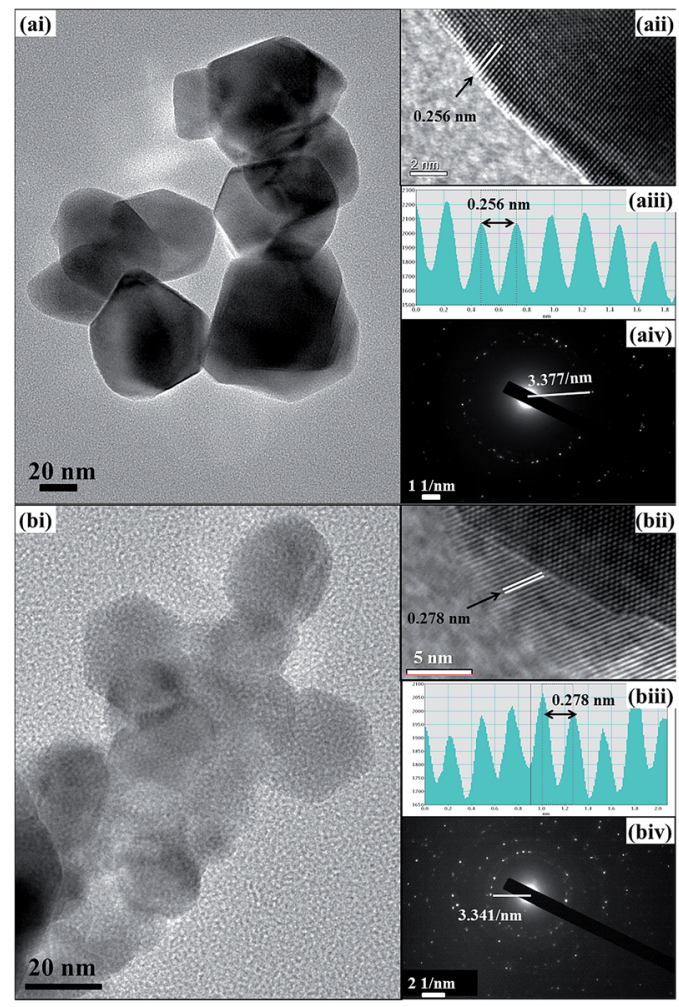

Fig. 2 TEM (ai, bi), HRTEM (aii, bii), lattice fringes (aiii, biii) and SAED (aiv, biv) images of (a) $\mathrm{ZnO}$ and (b) $\mathrm{C}$-doped $\mathrm{ZnO}$ calcined at $500^{\circ} \mathrm{C}$.

respectively. The angles between the labelled $d$-spacings are around $45^{\circ}$, corresponding to the dihedral angle between (100) and (101) surfaces. The HRTEM results reveal the largely exposed plane is (001) surface, which is further evidenced by the selected area electron diffraction patterns (SAED, Fig. 2(aiv) and (biv)). The circular multi-spots in the SAED images indicate the samples are polycrystals with (001) surface exposed preferentially.

Polymer surfactants have often used to control morphology and texture of ZnO crystals. ${ }^{27,28}$ Large $S_{\mathrm{BET}}$ of $12.5 \mathrm{~m}^{2} \mathrm{~g}^{-1}$ was ever observed on hierarchical C-doped $\mathrm{ZnO}$ prepared via a PEG-2000 directed thermal decomposition of $\mathrm{Zn}_{5}\left(\mathrm{CO}_{3}\right)_{2}(\mathrm{OH})_{6}$ at $500{ }^{\circ} \mathrm{C}, 7$ where the high porosity was attributed to $\mathrm{ZnO}$ interparticle slits and intra-flake voids created by release of volatile gases like $\mathrm{CO}$ and $\mathrm{H}_{2} \mathrm{O}$ during thermal treatments. However, there were no nano-pores or voids observed on our C-doped ZnO flakes (Fig. 2), which is reasonable since $\mathrm{ZnO}$ is easy to crystallise before forming regular pores around the polymer template. In our work, polymer surfactant F127 served as both

Table 1 Structural and textural properties of $\mathrm{ZnO}$ and $\mathrm{C}$-doped $\mathrm{ZnO}$ calcined at $500{ }^{\circ} \mathrm{C}$

\begin{tabular}{lllllr} 
& & \multicolumn{2}{l}{ Lattice parameters $(\AA)$} & & \\
Sample & Crystallite size $(\mathrm{nm})$ & $a=b$ & $c$ & Unit cell volume $\left(\AA^{3}\right)$ & $S_{\text {BET }}\left(\mathrm{m}^{2} \mathrm{~g}^{-1}\right)$ \\
\hline ZnO & 27.2 & 3.2490 & 5.2061 & 47.5936 & 7.1 \\
C-doped ZnO & 21.8 & 3.2448 & 5.2015 & 47.4275
\end{tabular}


carbon source and pore direct-agent to form $\mathrm{ZnO}$ nanoflakes in the C-doped ZnO preparation. The specific surface area $\left(S_{\mathrm{BET}}\right)$ of the C-doped $\mathrm{ZnO}$ is $17.1 \mathrm{~m}^{2} \mathrm{~g}^{-1}$ after calcinations at $500{ }^{\circ} \mathrm{C}$ (Table 1), approximately 2.5 times that $\mathrm{ZnO}$, and is larger than the hierarchical C-doped $\mathrm{ZnO}$ prepared via self-doping strategy. ${ }^{7}$ The larger $S_{\mathrm{BET}}$ of C-doped $\mathrm{ZnO}$ is associated with its smaller particle.

\subsection{Optical properties}

UV-vis diffuse adsorption spectra (UV-DRS) shown in Fig. 3(a) comparatively presents the different light absorption characteristics of pure and C-doped $\mathrm{ZnO}$ materials. In comparison with $\mathrm{ZnO}$, C-doped $\mathrm{ZnO}$ displays significant red shift of optical bandgap absorption edge into visible-light region as well as enhanced light absorption in the whole UV-visible band. Nonmetal doping into wideband metal-oxide photocatalysts, such as $\mathrm{N}$-doped $\mathrm{TiO}_{2}$, may effectively improve their visible-light absorption but at a price to reduce UV absorption. ${ }^{15,29}$ Although visible-light absorption is important for C-doped $\mathrm{ZnO}$ as a photocatalyst, enhanced UV absorbance would also benefit photocatalysis application of sunlight since UV is more efficient. ${ }^{14,16}$ Improvement of UV adsorption of C-doped $\mathrm{ZnO}$ is highly dependent on the synthesis strategy and precursors. For instance, enhanced UV adsorption was ever observed on Cdoped $\mathrm{ZnO}$ photocatalyst derived from zinc gluconate precursor, ${ }^{14}$ but C-doped ZnO synthesised via Vitamine $\mathrm{C}$ or self-doping strategies did not show improved adsorption of UV light. ${ }^{7,8}$
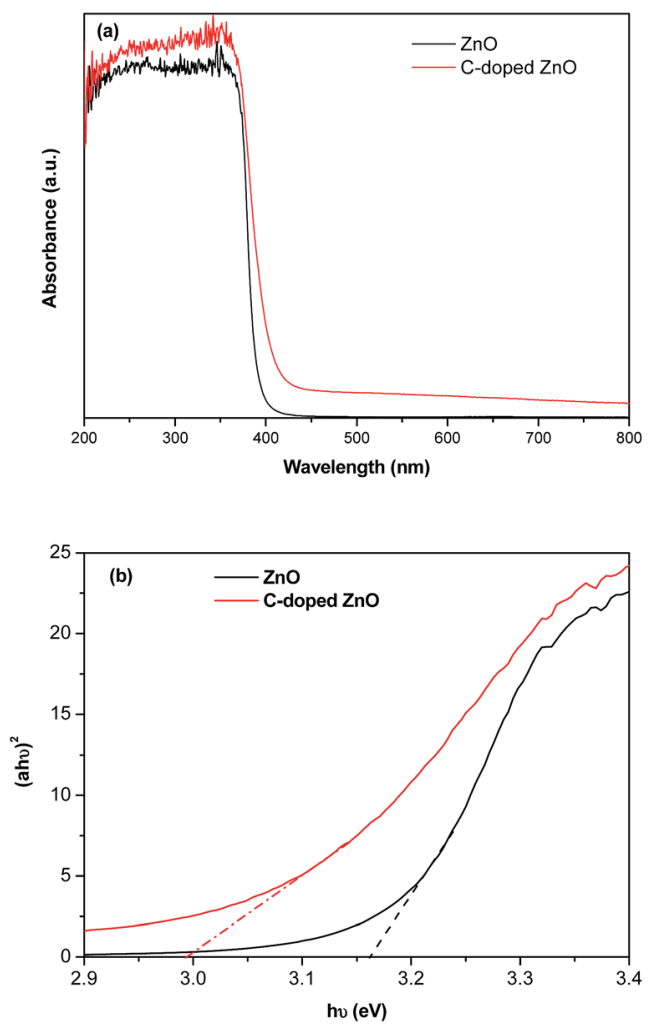

Fig. 3 UV-vis diffuse adsorption spectra (a) and corresponding $(a h \nu)^{2}$ vs. $h \nu$ plots for (b) $\mathrm{ZnO}$ and $\mathrm{C}$-doped $\mathrm{ZnO}$ calcined at $500{ }^{\circ} \mathrm{C}$.
Applying Kubelka-Munk rule the direct bandgap energies of $\mathrm{ZnO}(3.17 \mathrm{eV})$ and C-doped (2.98 eV) $\mathrm{ZnO}$ may be extracted precisely from their $(a h \nu)^{2} v s$. $h \nu$ plots as shown in Fig. 3(b). More importantly, the $(a h \nu)^{2} v s$. $h \nu$ plot in bandgap region for C-doped $\mathrm{ZnO}$ is linear similar to that of $\mathrm{ZnO}$, revealing the C-doping did not change direct electron transition characteristic of $\mathrm{ZnO}$ in badgap. ${ }^{7}$ Enhanced light harvesting and direct transition characteristics are highly desirable for doped $\mathrm{ZnO}$ materials in photocatalysis, opticoelectronic and solar cell applications.

Like $\mathrm{ZnO}$, the disrupt drop of light-absorption in bandgap region of $\mathrm{C}$-doped $\mathrm{ZnO}$ is observed clearly, suggesting that carbon was incorporated into $\mathrm{ZnO}$ matrix rather than laid down on $\mathrm{ZnO}$ surface. The $\mathrm{C}$ in $\mathrm{ZnO}$ lattice would revise $\mathrm{ZnO}$ 's band structure to introduce impurity midgap(s) and thus tune its bandgap. Besides bandgap light absorption, visible-light absorption on the C-doped $\mathrm{ZnO}$ is also tailed beyond $800 \mathrm{~nm}$ which is a typical red shift induced by impurity adsorption or oxygen-vacancies $\left(\mathrm{O}_{\mathrm{vac}}\right) \cdot{ }^{15,23}$ Advanced characterisations are necessary to determine $\mathrm{C}$-species and $\mathrm{O}_{\text {vac }}$ for understanding the nature of visible-light response on the C-doped $\mathrm{ZnO}$.

\subsection{Surface component and electron structure}

3.3.1 XPS analysis. XPS measurements were conducted to analyse surface species and valence band of both $\mathrm{ZnO}$ and C-doped $\mathrm{ZnO}$ so as to understand the origin of visible-light response of C-doped ZnO. Fig. 4(a)-(d) present the acquired C1s, O1s and Zn 2p core level as well as the valence-band XPS spectra of pure and C-doped $\mathrm{ZnO}$ calcined at $500{ }^{\circ} \mathrm{C}$, which clearly distinguished the differences between $\mathrm{ZnO}$ and $\mathrm{C}$-doped $\mathrm{ZnO}$ in both core level and valance electron bands.

As shown in Fig. 4(a), two sets of peaks are observed in the C1s XPS spectra for both pure and C-doped ZnO samples, including a large peak with binding energy (BE) ranging from 282 to $286.5 \mathrm{eV}$ and a satellite peaks at higher BE region. With the same BE centring at $288.7 \mathrm{eV}$, the satellite peaks for pure and $\mathrm{C}$-doped $\mathrm{ZnO}$ samples are attributed to the adsorbed $\mathrm{CO}_{2}$ and structural carbonate species containing $\mathrm{C}=0 .{ }^{7,13}$ Such species containing $\mathrm{C}=\mathrm{O}$ was ever predicted by DFT calculation and evidenced experimentally for C-anion-doped $\mathrm{TiO}_{2}{ }^{18,19}$ whereas the C1s satellite peak is broader, revealing a portion of such $\mathrm{C}$ species would be from carbonate species trapped in C-doped ZnO matrix or existing incompletely decomposed carbonate precursors. $^{7}$

The major C1s XPS peak of C-doped $\mathrm{ZnO}$ is asymmetric and distinct from that of $\mathrm{ZnO}$. The main peak centres at $284.6 \mathrm{eV}$ for $\mathrm{ZnO}$ is symmetric and can be ascribed to adventitious hydrocarbon. However, the asymmetric major peak of C1s XPS for C-doped $\mathrm{ZnO}$ centres at $284.4 \mathrm{eV}, 0.2 \mathrm{eV}$ red-shift relative to that in $\mathrm{ZnO}$, which is resulting from peaks overlap between contaminant carbon and other carbon species. The major C1s XPS peak was therefore fitted into 4 peaks: the largest one at $284.6 \mathrm{eV}$ can be assigned to adventitious hydrocarbon, while $286.2 \mathrm{eV}$ and $283.8 \mathrm{eV}$ are due to $\mathrm{Zn}-\mathrm{O}-\mathrm{C}$ and $\mathrm{Zn}-\mathrm{C}$ bonds, ${ }^{22}$ respectively. The smallest fitted peak at $282.9 \mathrm{eV}$ is associated to $\mathrm{Zn}-\mathrm{C}$ bond connected with oxygen-vacancy $\left(\mathrm{O}_{\mathrm{vac}}\right)$ since additional electron density would be imposed from negative- 

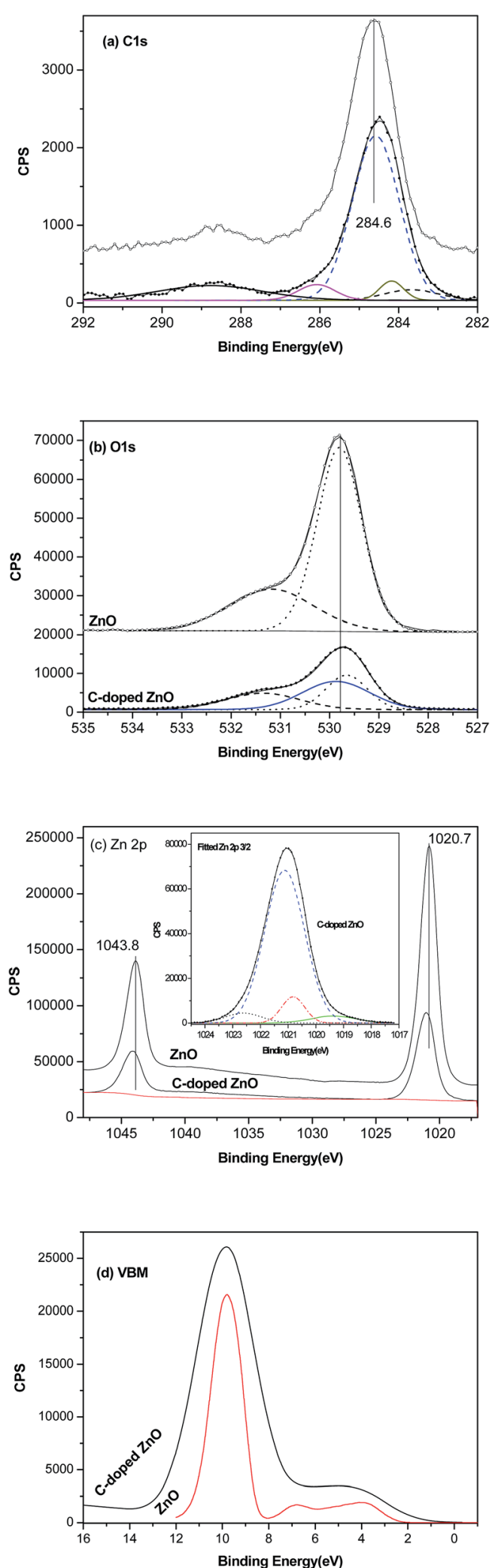

Fig. 4 Core level XPS spectra of (a) C1s, (b) O1s, (c) Zn $2 p$ and (d) valence band in $\mathrm{ZnO}$ and $\mathrm{C}$-doped $\mathrm{ZnO}$ photocatalysts calcined at $500^{\circ} \mathrm{C}$. charged $\mathrm{O}_{\mathrm{vac}}$ onto $\mathrm{C}$ in the $\mathrm{Zn}-\mathrm{C}-\mathrm{O}_{\text {vac }}$ bond. It has been well accepted that $\mathrm{O}_{\mathrm{vac}}$ may result in bandgap narrowing, ${ }^{23}$ therefore it is necessary to address the contributions of $\mathrm{Zn}-\mathrm{C}$ and $\mathrm{O}_{\mathrm{vac}}$ to the visible-light response of C-doped $\mathrm{ZnO}$.

The areas of C1s XPS peaks due to $\mathrm{Zn}-\mathrm{O}-\mathrm{C}, \mathrm{Zn}-\mathrm{C}$ and $\mathrm{Zn}-\mathrm{C}-\mathrm{O}_{\text {vac }}$ are almost the same. In principle, zinc carbonate species would not cause visible light response in $\mathrm{ZnO},{ }^{7}$ hence, it can be concluded the visible-light-response should be associated directly with $\mathrm{Zn}-\mathrm{C}$ species and $\mathrm{Zn}-\mathrm{C}-\mathrm{O}_{\text {vac }}$ induced by carbon-doping. As discussed in UV-vis-DRS, $\mathrm{O}_{\text {vac }}$ would mainly be responsible for the light response in the whole visible-light range that accounts for grey colour of our C-doped $\mathrm{ZnO}$, but also influences bandgap adsorption as discussed in electronic structure section.

Fig. 4(b) presents the O1s XPS of pure and C-doped $\mathrm{ZnO}$ calcined at $500{ }^{\circ} \mathrm{C}$. For pure $\mathrm{ZnO}$, a large $\mathrm{O} 1 \mathrm{~s}$ locates at $529.8 \mathrm{eV}$ is due to $\mathrm{Zn}-\mathrm{O}$ bonds in wurtzite $\mathrm{ZnO}$ crystal, and a shoulder peak $(531.3 \mathrm{eV})$ of $25 \%$ height to the major peak may be due to surface chemical adsorbed oxygen species, such as $\mathrm{OH}^{-}$group and carbonates. ${ }^{22}$ The O1s XPS of C-doped $\mathrm{ZnO}$ encompasses a major peak at $529.7 \mathrm{eV}$ along with a shoulder peak $(531.5 \mathrm{eV})$ of $33 \%$ intensity to the major peak, suggesting the O1s components locates in different environment from those in $\mathrm{ZnO}$. O1s XPS of C-doped $\mathrm{ZnO}$ were fitted into 3 peaks centring at 531.5, 529.9 and $529.7 \mathrm{eV}$. The peak at $531.5 \mathrm{eV}$ may be ascribed to surface adsorbed oxygen species ( $\mathrm{OH}$ group) and carbonate species (i.e. $\mathrm{C}-\mathrm{O}$ and $\mathrm{C}=\mathrm{O}$ bonds). The peak at $529.6 \mathrm{eV}$ is assigned to $\mathrm{O}^{2-}$ ions of $\mathrm{Zn}-\mathrm{O}$ bonds in Wurtzite structure with $\mathrm{Zn}^{2+}$ in hexagonal coordinations, and O1s peak at $529.9 \mathrm{eV}$ can be reasonably attributed to $\mathrm{Zn}-\mathrm{O}_{\mathrm{vac}}$ and $\mathrm{Zn}-\mathrm{O}-\mathrm{C}$ bonds because $\mathrm{C}$-dopant and $\mathrm{O}_{\text {vac }}$ usually induce blue shift of $\mathrm{Zn}-\mathrm{O}$ bond. ${ }^{23}$ It is difficult to determine the concentrations of $\mathrm{O}_{\mathrm{vac}}$ and $\mathrm{Zn}-\mathrm{C}-\mathrm{O}$ or $\mathrm{Zn}-\mathrm{O}-\mathrm{C}$ species from O1s XPS because the peaks are heavily overlapped.

Fig. 4(c) compares the Zn 2p XPS spectra of ZnO and C-doped $\mathrm{ZnO}$. It can be clearly seen that the $\mathrm{Zn} 2 \mathrm{p}_{3 / 2}$ and $2 \mathrm{p}_{5 / 2} \mathrm{XPS}$ lines in C-doped $\mathrm{ZnO}$ are blue shifted $(0.2 \mathrm{eV})$ systematically relative to pure $\mathrm{ZnO}$. The BE difference between $\mathrm{Zn} 2 \mathrm{p}_{3 / 2}$ and $2 \mathrm{p}_{5 / 2}$ XPS lines remains $23.1 \mathrm{eV}$ for $\mathrm{ZnO}$ and $\mathrm{C}$-doped $\mathrm{ZnO}$, suggesting $\mathrm{Zn}$ is in $\mathrm{Zn}^{2+}$ state for the two samples. ${ }^{22}$ The $\mathrm{Zn} 2 \mathrm{p}_{3 / 2}$ state was further fitted into 4 peaks (inserted in Fig. 4(c)) corresponding to $\mathrm{Zn}-\mathrm{C}$ (1019.3, 4.3\%), Zn-O-C (1020.8 eV, 8.2\%), Zn-O (1021.1 $\mathrm{eV}, 82.6 \%)$ and $\mathrm{Zn}-\mathrm{O}_{\text {vac }}(1022.6 \mathrm{eV}, 4.9 \%)$ bonds, respectively. The results reveal the carbon concentration is around 12.5 atm\% relative to $\mathrm{Zn}, 2.5$ times that $\mathrm{O}_{\text {vac }}$ concentration. However, the concentration of $\mathrm{Zn}-\mathrm{C}$ carbide species is nearly equal to that of $\mathrm{O}_{\mathrm{vac}}$, suggesting the formation of each $\mathrm{Zn}-\mathrm{C}$ bond would create at least one $\mathrm{O}_{\text {vac }}$ site which agrees with the C1s XPS analysis.

Valence band (VB) XPS is a powerful tool to investigate the influence of impurity on the band structure of semiconductors. Fig. 4(d) comparatively shows VB XPS spectra acquired on ZnO and C-doped ZnO. It clearly shows the C-doping not only redshifts valance band maximum (VBM) energy but also expands the VB band width. The VBM of ZnO is approximately $2.24 \mathrm{eV}$ relative to vacuum level yet lifts up to $1.33 \mathrm{eV}$ once doped with carbon, revealing $\mathrm{C}$-doping in this case is an n-type doping. In 
addition, the $\mathrm{ZnO} \mathrm{VB}$ with width about $6.0 \mathrm{eV}$ is more localised with clear discrete energy levels than the $\mathrm{VB}$ of C-doped $\mathrm{ZnO}$. The VB width of C-doped $\mathrm{ZnO}$ is greater than $7.0 \mathrm{eV}$ and overlapped with deeper energy level, revealing its VB electrons are delocalised and more dispersive.

3.3.2 Electronic structure. CASTEP code was used to simulate the electron structures of wurtzite $\mathrm{ZnO}$ and C-doped ZnO crystals. Fig. 5(a) and (b) compares the simulated band structures of $\mathrm{ZnO}$ and C-doped $\mathrm{ZnO}$, showing C-doped $\mathrm{ZnO}$ possesses much higher electron density of state (DOS) because of C-doping induced electron delocalisation. A new electron density of sate at $\sim 10 \mathrm{eV}$ due to $\mathrm{C} 2 \mathrm{~s}$ state is also observed in the C-doped $\mathrm{ZnO}$. The calculated $E_{\mathrm{g}}$ of $\mathrm{ZnO}$ is $0.97 \mathrm{eV}$, which is much smaller than experimental value $(3.17 \mathrm{eV})$ due to the choice of GGA exchange-correlation energy in DFT simulation. However, it is fairly larger than $E_{\mathrm{g}}$ calculated using ultrasoft pseudopotential, ${ }^{7}$ indicating the advantage of norm-conserving pseudopotential over ultrasoft pseudopotential in band structure simulation. Simulation using GGA $+\mathrm{U}$ function may predict $E_{\mathrm{g}}$ closer to experimental value while it is rather expensive since it estimates $E_{\mathrm{g}}$ based on GGA geometry optimisation. ${ }^{17,18}$ Within our approximation, GGA modelling provided here sufficient accuracy for the influence of C-dopant on the VB position and $\mathrm{C}$ donor states relative to the VBM.

The calculated VB width is approximately 5.5 and $6.1 \mathrm{eV}$ for $\mathrm{ZnO}$ and C-doped $\mathrm{ZnO}$, respectively, which are well consistent with the VB XPS results. In addition, the conductance band minimum (CBM) was dropped down around $1.0 \mathrm{eV}$ compared to
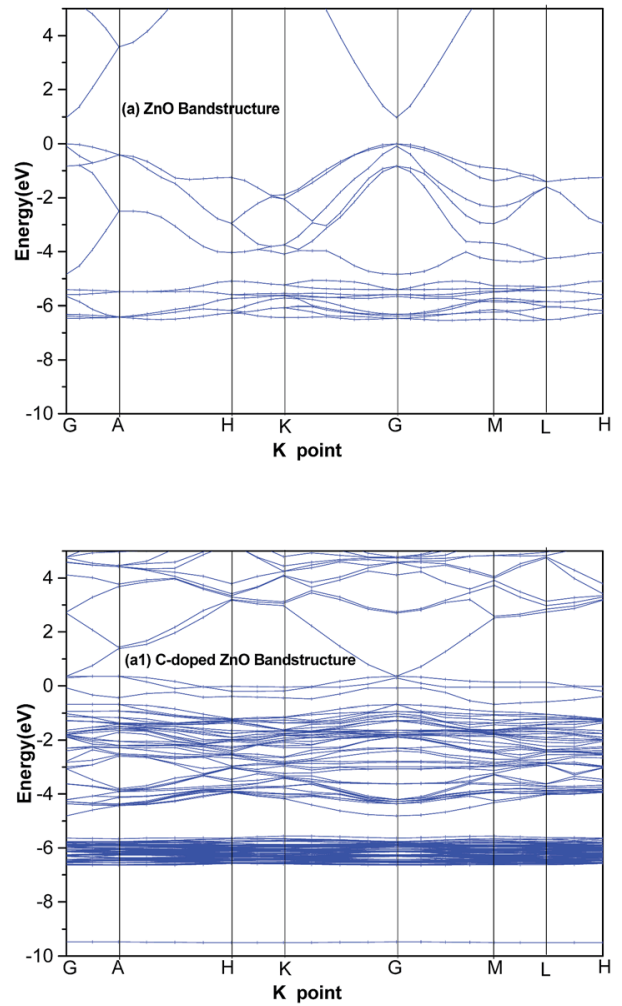

Fig. 5 Simulated band structures of Wurtzite (a) ZnO and (b) C-doped $\mathrm{ZnO}$.
ZnO. The valance band maximum (VBM) and conductance band minimum (CBM) of the pure and $\mathrm{C}$-doped $\mathrm{ZnO}$ are both locating at $G$ points, indicating their direct electron transition in bandgap region that are convinced by the experimental UV-visDRS characterisation results (Fig. 3(b)). The VBM of C-doped $\mathrm{ZnO}$ joints with its CBM at $G$ point leading to vanishing of bandgap of C-doped $\mathrm{ZnO}$, which is mainly due to a new additional C 2p state on top of O 2p state of $\mathrm{ZnO}$ (Fig. 7(c) and S1a $\dagger$ ) and the underestimated $E_{\mathrm{g}}$.

The enhanced DOS, narrowed bandgap and extended bandwidth of $\mathrm{C}$-doped $\mathrm{ZnO}$ relative to $\mathrm{ZnO}$ are further detailed by the PDOS plots shown in Fig. 6(a) and (b). It can be seen the $\mathrm{VB}$ of $\mathrm{ZnO}$ is mainly composed of $\mathrm{p}$ state electrons well dispersed in the whole $\mathrm{VB}$ region as well as the $\mathrm{s}$ and $\mathrm{d}$ states appearing at slightly deeper VB band. The major component of $\mathrm{ZnO}$ valance band maximum (VBM) is $\mathrm{p}$ state and involves a small amount of $d$ state electrons. The conductance band minimum (CBM) of $\mathrm{ZnO}$ is only containing s state electrons. In contrast, the VB of C-doped $\mathrm{ZnO}$ is mainly composed of p state electrons but the $\mathrm{s}$ and $\mathrm{d}$ state electrons also contributed significantly to its VBM. It is notable that the CBM of C-doped $\mathrm{ZnO}$ contains $\mathrm{s}$ and $\mathrm{p}$ state electrons.

Combined Fig. 6 and the element PDOS results presented in Fig. $7(\mathrm{a}-\mathrm{c})$ and $\mathrm{S} 1(\mathrm{a}, \mathrm{b}), \dagger$ it can be concluded that the $\mathrm{VB}$ of $\mathrm{ZnO}$ is composed of hybridised $\mathrm{O} 2 \mathrm{p}$ and $\mathrm{Zn} 3 \mathrm{~d}$ states, and its $\mathrm{CB}$ comprises of $\mathrm{Zn} 4 \mathrm{~s}$ states and $\mathrm{O} 2 \mathrm{p}$ at higher energy level. From the $\mathrm{Zn}$ and $\mathrm{O}$ PDOS plots in Fig. S1, $\dagger$ it may be found ZnO VBM is mainly composed of $\mathrm{O} 2 \mathrm{p}$ sates hybridising with a little $\mathrm{Zn} 3 \mathrm{~d}$
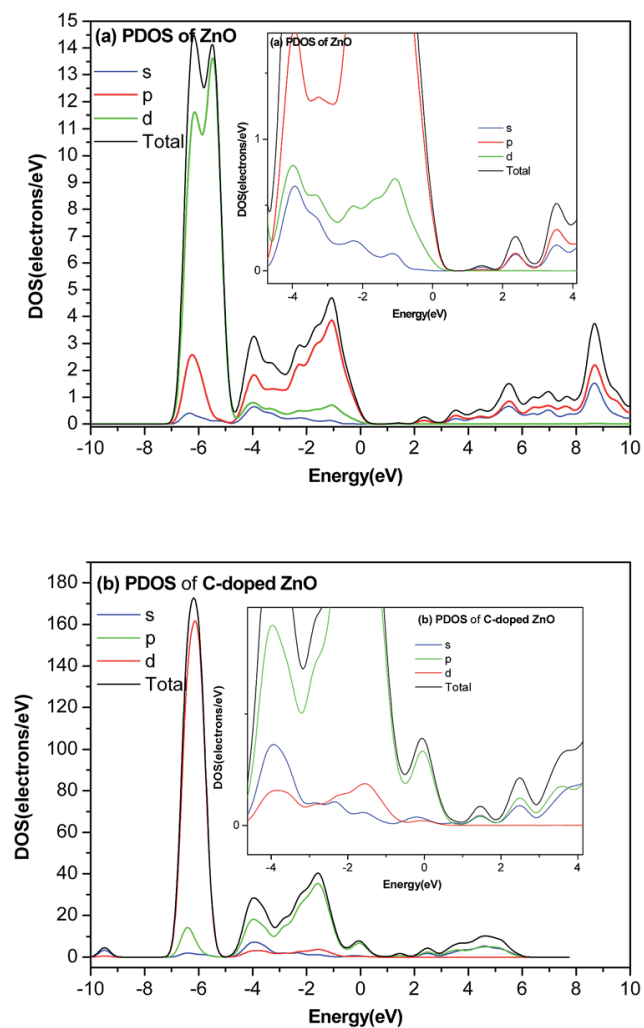

Fig. 6 PDOS of Wurtzite structured (a) $\mathrm{ZnO}$ and (b) C-doped $\mathrm{ZnO}$ crystals. 

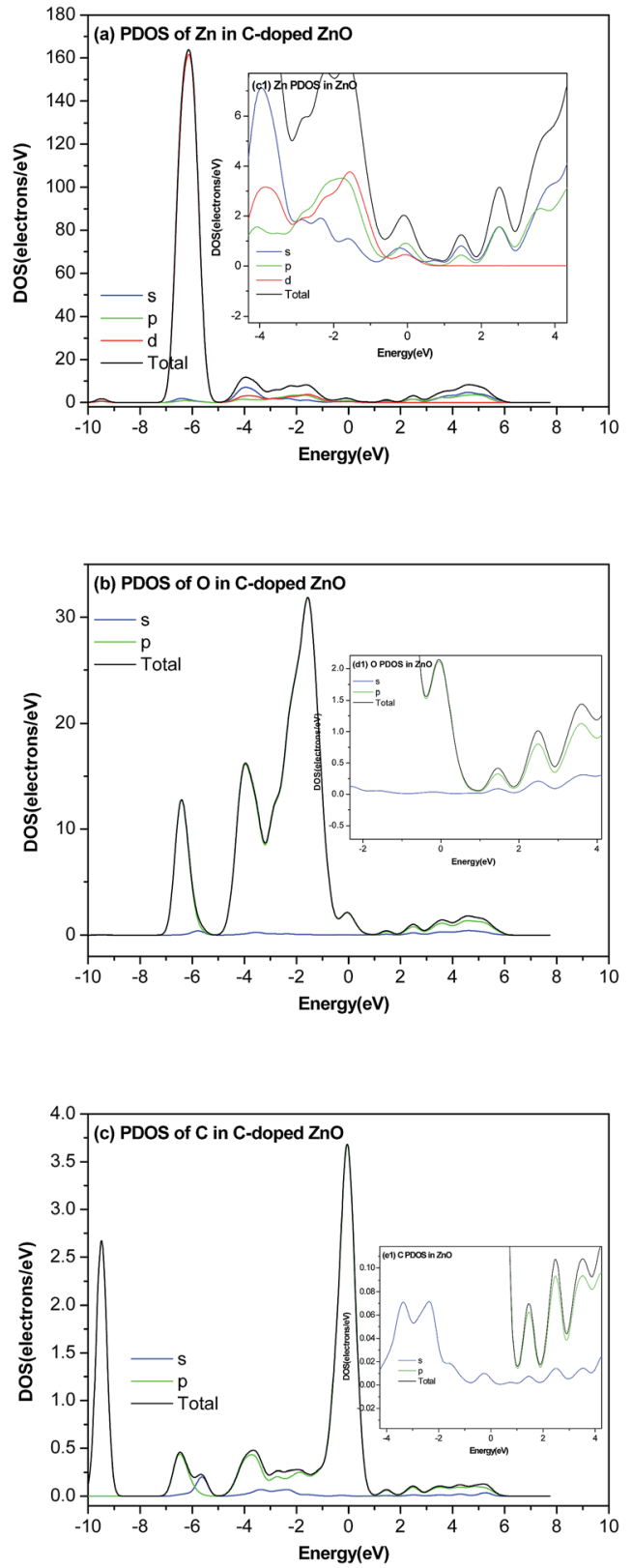

Fig. 7 PDOS of Zn (a), O (b) and C (c) of C-doped ZnO Wurtzite crystal. Insets correspond to amplified PDOS around bandgap region.

state, while $\mathrm{Zn} 4 \mathrm{~s}$ state dominates the CBM. Once C is incorporated into $\mathrm{ZnO}$, new electron states are appeared at VBM and pinned at Fermi level. The VBM are occupied by $\mathrm{C} 2 \mathrm{p}$ state (Fig. 7(c)) with hybridised Zn 3d and 4 s states (Fig. 7(a) and (b) and insets). The CBM of C-doped $\mathrm{ZnO}$ is dominated by state with almost equal amount of p state. Apparently, the VBM and CBM components of C-doped $\mathrm{ZnO}$ distinctly distinguish from those of $\mathrm{ZnO}$ and its reduced bandgap is mainly due to new states arisen from C-doping. The components of CBM in C-doped $\mathrm{ZnO}$ are also changed correspondingly in comparison to $\mathrm{ZnO}$.

It is essential to further quantitatively investigate the components of the new additional states on top of VBM and CBM which disclose the roles of C-doping in narrowing bandgap of C-doped ZnO. As shown in Fig. 7(a-c), the detailed PDOS of Zn, O and $\mathrm{C}$ in C-doped ZnO verify its VBM state are mainly composed of $\mathrm{C} 2 \mathrm{p}$ sate ( $\sim 50 \%), \mathrm{O} 2 \mathrm{p}(\sim 25 \%)$ and hybridised $4 \mathrm{~s}$ and $3 \mathrm{~d}$ states $(25 \%)$ of $\mathrm{Zn}$. The new $\mathrm{O}$ and $\mathrm{Zn}$ states at VBM can be attributed to oxygen vacancies induced by $\mathrm{C}$-doping so as to remain the overall charge neutrality after substitution of $\mathrm{O}^{2-}$ by $\mathrm{C}^{4-}$ in $\mathrm{ZnO}$ matrix. ${ }^{18}$ Although $\mathrm{Zn} 4 \mathrm{~s}$ state dominates CBM of C-doped ZnO, O 2p and 2s states also contribute around 25\% CBM while the contribution of C-dopant (2p state) to the CBM is negligible.

Combining the experimental VBM XPS and theoretical PDOS analyses we can now draw an elusive scheme of band structure of C-doped $\mathrm{ZnO}$ as shown in Fig. 8, which clearly shows the bandgap narrowing of $\mathrm{C}$-doped $\mathrm{ZnO}$ is mainly induced by $\mathrm{C}$-doping and derived $\mathrm{O}_{\mathrm{vac}}$ : the new states of $\mathrm{C} 2 \mathrm{p}$ and $\mathrm{O}_{\mathrm{vac}}{ }^{-}$ related $\mathrm{O} 2 \mathrm{p}, \mathrm{Zn} 3 \mathrm{~d}$ and $4 \mathrm{~s}$ lift up VBM of $\mathrm{ZnO}$; the $\mathrm{Zn} 4 \mathrm{~s}$ and $\mathrm{O}$ $2 \mathrm{p}$ states of $\mathrm{O}_{\mathrm{vac}}$ comprise of the CBM in C-doped $\mathrm{ZnO}$ which pushes the CBM down to lower energy level. In all, it is the additional energy levels induced by $\mathrm{C}$-doping and $\mathrm{O}_{\text {vac }}$ narrowing the bandgap of $\mathrm{C}$-doped $\mathrm{ZnO}$ in comparison to $\mathrm{ZnO}$.

\subsection{Photocatalytic activity}

Fig. 9(a) shows the time-dependent absorbance spectra of MB on C-doped $\mathrm{ZnO}$ under visible light illumination, revealing the gradual decolourisation of $\mathrm{MB}$ on $\mathrm{C}$-doped $\mathrm{ZnO}$ under visible light irradiation. The photodegradation should be induced by the photocatalytic reaction because MB degradation is negligible without photocatalyst and no degradation was observed on the photocatalysts in dark. Despite the fact that C-doped $\mathrm{ZnO}$ possessed enhanced light absorption, ZnO exhibited notably higher photoactivity in $\mathrm{MB}$ degradation than C-doped $\mathrm{ZnO}$ under visible light irradiation (Fig. 9(b)). It is well known that photocatalysis follows the first order kinetics law, so that the apparent reaction kinetics constant, $k$, can be extracted from the slope of plot of $-\ln \left(c / c_{0}\right) v s$. reaction time. ${ }^{7,14,15}$ The calculated $k$ values for $\mathrm{ZnO}$ and $\mathrm{C}$-doped $\mathrm{ZnO}$ are 0.009 and $0.006 \mathrm{~min}^{-1}$, respectively. ZnO possesses better activity and larger $k_{\mathrm{ZnO}}$ than C-doped $\mathrm{ZnO}$, suggesting the visible-light-driven $\mathrm{MB}$ photodecomposition should not be dominated by bandgap excitation.

Owing to the wide bandgap, valence band electrons of $\mathrm{ZnO}$ cannot be excited by visible light so that MB photodegradation
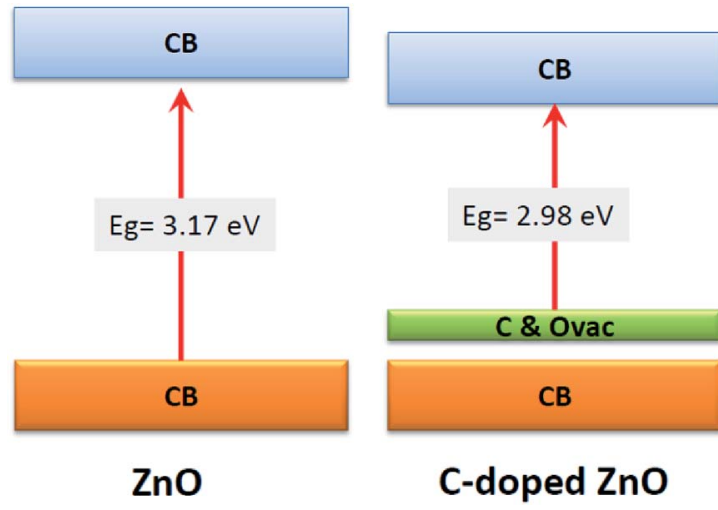

C-doped ZnO

Fig. 8 Schematic band structures of $\mathrm{ZnO}$ and $\mathrm{C}$-doped $\mathrm{ZnO}$ crystals. 

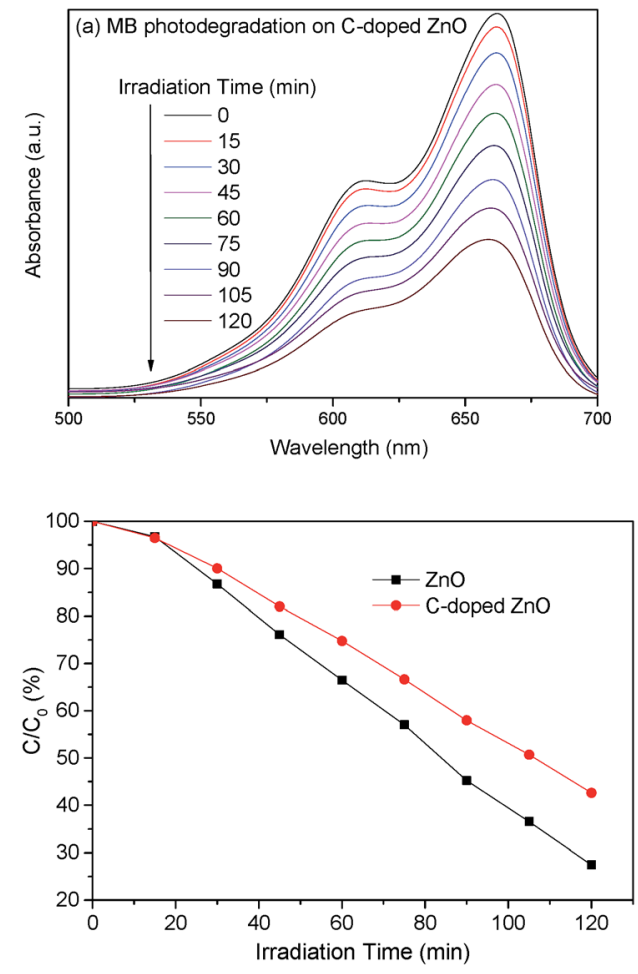

Fig. 9 (a) UV-vis spectra on C-doped $\mathrm{ZnO}$ and (b) photocatalytic activity on $\mathrm{ZnO}$ and $\mathrm{C}$-doped $\mathrm{ZnO}$ for Methylene degradation.

on $\mathrm{ZnO}$ is attributed to dye-sensitised photocatalysis. Under visible light illumination $\mathrm{MB}$ is excited by light of wavelength shorter than its characteristic absorption wavelength $(662 \mathrm{~nm})$ and then injects photoexcited electrons into $\mathrm{ZnO}$ conduction band (CB). The electrons injected onto $\mathrm{ZnO} \mathrm{CB}$ react with dissolved oxygen and give rise to active oxygen species which can decompose the excited MB. ${ }^{7,14}$ In contrast, C-doped $\mathrm{ZnO}$ may be excited by visible light due to its narrowed bandgap to lift valence electrons onto CB and leave holes on VB. Furthermore, C-doped $\mathrm{ZnO}$ should have been shown stronger dyesensitising effect than $\mathrm{ZnO}$ since C-doped $\mathrm{ZnO}$ possesses larger $S_{\mathrm{BET}}$ and thus sensitising opportunity due to higher $\mathrm{MB}$ adsorption amount. It seemed the heavy C-doped $\mathrm{ZnO}$ should be more active, whereas the experimental results showed it is less active than $\mathrm{ZnO}$, suggesting heavy C-doping would deteriorate the dye-sensitised photodegradation. It is reasonable to conclude that bandgap excitation of the C-doped $\mathrm{ZnO}$ contributes a little to the overall $\mathrm{MB}$ photodegradation in comparison to dye-sensitisation under visible-light illumination. The fact is that heavy C-doping and derived $\mathrm{O}_{\mathrm{vac}}$ correspondingly would serve as recombination centres in the photoreaction which reduce dye-sensitising effects by trapping the electrons from excited dyes and thus deteriorate photodegradation on C-doped $\mathrm{ZnO}$ relative to $\mathrm{ZnO}$.

In general, the enhanced light absorption corresponds to enhanced photoexcitation while the photo excitons are prone to recombination leading to almost 95\% loss of absorbed light energy. ${ }^{\mathbf{4 , 5 2 4}}$ The charge recombination centres may be overloaded dopants or structure deficiencies, for instance $\mathrm{O}_{\mathrm{vac}}$.
Previous report evidenced there exists optimum C-doping range for promoting visible-light-driven photoreactivity while photocatalytic activity would be lower beyond the suitable C-doping levels. ${ }^{7}$ C-doped ZnO containing 2.7 at.\% C showed higher activity than that containing 0.41 at.\% C-dopant. ${ }^{8}$ However, the roles of $\mathrm{O}_{\text {vac }}$ were not paid enough attention. We did find the photocatalytic activity may be improved for light-C-doped $\mathrm{ZnO}$ prepared through reducing F127 amount (ESI, Fig. S2 $\dagger$ ), while this research focused on the heavy C-doping sample because it is more important to unveil the function of coexistence of $\mathrm{C}^{4-}$ and $\mathrm{O}_{\mathrm{vac}}$. Despite the fact that suitable amount of $\mathrm{O}_{\mathrm{vac}}$ can extend light absorption into visible light region and improve photocatalytic activity, the photoreactivity will drop dramatically if $\mathrm{O}_{\mathrm{vac}}$ concentration is greater than certain amount. ${ }^{\mathbf{1 5 , 2 3}}$ In this research, the $\mathrm{C}$-doping level is quite high with almost 4.3 at.\% carbide-based $\mathrm{C}^{4-}$ coexisting with comparable amount of $\mathrm{O}_{\text {vac }}$ in the C-doped $\mathrm{ZnO}$. Hence, the low visible-light-driven photocatalytic activity on the C-doped $\mathrm{ZnO}$ was tentatively assigned to the synergistic consequences of the overloaded C-dopants and $\mathrm{O}_{\text {vac }}$ that favour the recombination of photogenerated charge carriers under irradiation.

\section{Conclusion}

C-doped ZnO nanoflakes with large surface area were successfully synthesised via a pyrolysis process using Pluronic F127 as polymer-directed agent. The C-doping leads to enhanced UV and visible light absorption yet does not affect the electron (direct) transition characteristic of $\mathrm{ZnO}$. The direct bandgap of the $\mathrm{C}$-doped $\mathrm{ZnO}$ is $2.98 \mathrm{eV}$ though its light adsorption tails beyond visible light region because of co-existing oxygen vacancies and C-dopants.

VBM XPS evidenced the C-doping expends VB width of $\mathrm{ZnO}$ and lifts its VBM energy as well as draws the CBM down towards Fermi level, leading to narrowed bandgap. DFT simulations reveal the origin of visible-light-response of C-doped $\mathrm{ZnO}$ is also related to additional bandgap electron states (midgap energy levels) arisen from C-doping and correspondingly created $\mathrm{O}_{\mathrm{vac}}$ stemmed from C-doping. Distinguished from $\mathrm{O} 2 \mathrm{p}$ and $\mathrm{Zn} 4 \mathrm{~s}$ states composing ZnO VBM and CBM, the VBM of C-doped ZnO is dominated with $\mathrm{C} 2 \mathrm{p}$ state and its CBM mainly contains $\mathrm{Zn} 4 \mathrm{~s}$ along with additional states of $\mathrm{Zn} 3 \mathrm{~d}$ and hybridised states of $\mathrm{O}$ $2 \mathrm{~s}$ and $\mathrm{O} 2 \mathrm{p}$ of $\mathrm{O}_{\mathrm{vac}}$. Although the C-doped $\mathrm{ZnO}$ showed enhanced light absorption, its visible-light-driven activity in $\mathrm{MB}$ photodegradation is worse than that $\mathrm{ZnO}$ because the $\mathrm{C}$-doping and corresponding $\mathrm{O}_{\text {vac }}$ led to significant charge recombination.

\section{Acknowledgements}

We acknowledge the financial support from the University of Southamtpon (innovation adventure fund), Shell Foundation (Sir John Houghton Fellowship), HEFCE (Zepler institute stimulus fund) and King Abdulaziz City for Sceince and Technology (KACST, project no: 29-280). We thank Ms Nazanin RashidiAlavijeh in the Inorganic Chemistry Laboratory at Oxford University for her help to collect and discuss XPS data of $\mathrm{ZnO}$. 
LC, XC and ZJ thank the support from EU - Ecofuel project (European Commission - FP7, 246772).

\section{References}

1 A. Kubacka, M. Fernández-García and G. Colón, Chem. Rev., 2011, 112, 1555-1614.

2 R. E. Galian and J. Perez-Prieto, Energy Environ. Sci., 2010, 3, 1488-1498.

3 Y. Tachibana, L. Vayssieres and J. R. Durrant, Nat. Photonics, 2012, 6, 511-518.

4 A. Ajmal, I. Majeed, R. N. Malik, H. Idriss and M. A. Nadeem, RSC Adv., 2014, 4, 37003-37026.

5 M. Pelaez, N. T. Nolan, S. C. Pillai, M. K. Seery, P. Falaras, A. G. Kontos, P. S. M. Dunlop, J. W. J. Hamilton, J. A. Byrne, K. O'Shea, M. H. Entezari and D. D. Dionysiou, Appl. Catal., B, 2012, 125, 331-349.

6 M. N. Chong, B. Jin, C. W. K. Chow and C. Saint, Water Res., 2010, 44, 2997-3027.

7 S. Liu, C. Li, J. Yu and Q. Xiang, CrystEngComm, 2011, 13, 2533-2541.

8 S. Cho, J.-W. Jang, J. S. Lee and K.-H. Lee, CrystEngComm, 2010, 12, 3929-3935.

9 Y.-G. Lin, Y.-K. Hsu, Y.-C. Chen, L.-C. Chen, S.-Y. Chen and K.-H. Chen, Nanoscale, 2012, 4, 6515-6519.

10 S.-M. Lam, J.-C. Sin, A. Z. Abdullah and A. R. Mohamed, Desalin. Water Treat., 2012, 41, 131-169.

11 F. Wang, L. Liang, L. Shi, M. Liu and J. Sun, Dalton Trans., 2014, 43, 16441-16449.

12 D. Chen, Z. Wang, T. Ren, H. Ding, W. Yao, R. Zong and Y. Zhu, J. Phys. Chem. C, 2014, 118, 15300-15307.

13 H. Pan, J. Yi, L. Shen, R. Wu, J. Yang, J. Lin, Y. Feng, J. Ding, L. Van and J. Yin, Phys. Rev. Lett., 2007, 99, 127201.

14 O. Haibo, H. J. Feng, L. Cuiyan, C. Liyun and F. Jie, Mater. Lett., 2013, 111, 217-220.
15 Z. Jiang, L. Kong, F. S. Alenazey, Y. Qian, L. France, T. Xiao and P. P. Edwards, Nanoscale, 2013, 5, 5396-5402.

16 S. U. M. Khan, M. Al-Shahry and W. B. Ingler, Science, 2002, 297, 2243-2245.

17 K. Yang, Y. Dai, B. Huang and M.-H. Whangbo, Chem. Mater., 2008, 20, 6528-6534.

18 K. Yang, Y. Dai, B. Huang and M.-H. Whangbo, J. Phys. Chem. C, 2009, 113, 2624-2629.

19 W. Ren, Z. Ai, F. Jia, L. Zhang, X. Fan and Z. Zou, Appl. Catal., $B, 2007,69,138-144$.

20 D. E. Zhang, M. Y. Wang, J. J. Ma, G. Q. Han, S. A. Li, H. Zhao, B. Y. Zhao and Z. W. Tong, Funct. Mater. Lett., 2014, 07, 1450026.

21 S. T. Tan, X. W. Sun, Z. G. Yu, P. Wu, G. Q. Lo and D. L. Kwong, Appl. Phys. Lett., 2007, 91, 072101.

22 D. K. Mishra, J. Mohapatra, M. K. Sharma, R. Chattarjee, S. K. Singh, S. Varma, S. N. Behera, S. K. Nayak and P. Entel, J. Magn. Magn. Mater., 2013, 329, 146-152.

23 J. Wang, Z. Wang, B. Huang, Y. Ma, Y. Liu, X. Qin, X. Zhang and Y. Dai, ACS Appl. Mater. Interfaces, 2012, 4, 4024-4030.

24 S. G. Kumar and K. S. R. K. Rao, RSC Adv., 2015, 5, 33063351.

25 J. P. Perdew, K. Burke and M. Ernzerhof, Phys. Rev. Lett., 1997, 78, 1396.

26 H. J. Monkhorst and J. D. Pack, Phys. Rev. B: Condens. Matter Mater. Phys., 1976, 13, 5188-5192.

27 A. Bagabas, A. Alshammari, M. Aboud and H. Kosslick, Nanoscale Res. Lett., 2013, 8, 516.

28 H. Li, Y. Zhang and J. Wang, J. Am. Ceram. Soc., 2012, 95, 1241-1246.

29 R. Asahi, T. Morikawa, T. Ohwaki, K. Aoki and Y. Taga, Science, 2001, 293, 269-271. 